\title{
Kajian tentang Perumusan Hipotesis Statistik Dalam Pengujian Hipotesis Penelitian
}

\author{
1)M. Zaki, 2)Saiman \\ 1), 2)Dosen Program Studi Pendidikan Matematika FKIP Universitas Samudra, Langsa, Aceh \\ E-mail: acutzaki@unsam.ac.id
}

\begin{tabular}{|c|c|}
\hline Article Info & Abstract \\
\hline $\begin{array}{l}\text { Article History } \\
\text { Received: } 2021-01-12 \\
\text { Revised: 2021-02-01 } \\
\text { Published: 2021-03-16 }\end{array}$ & 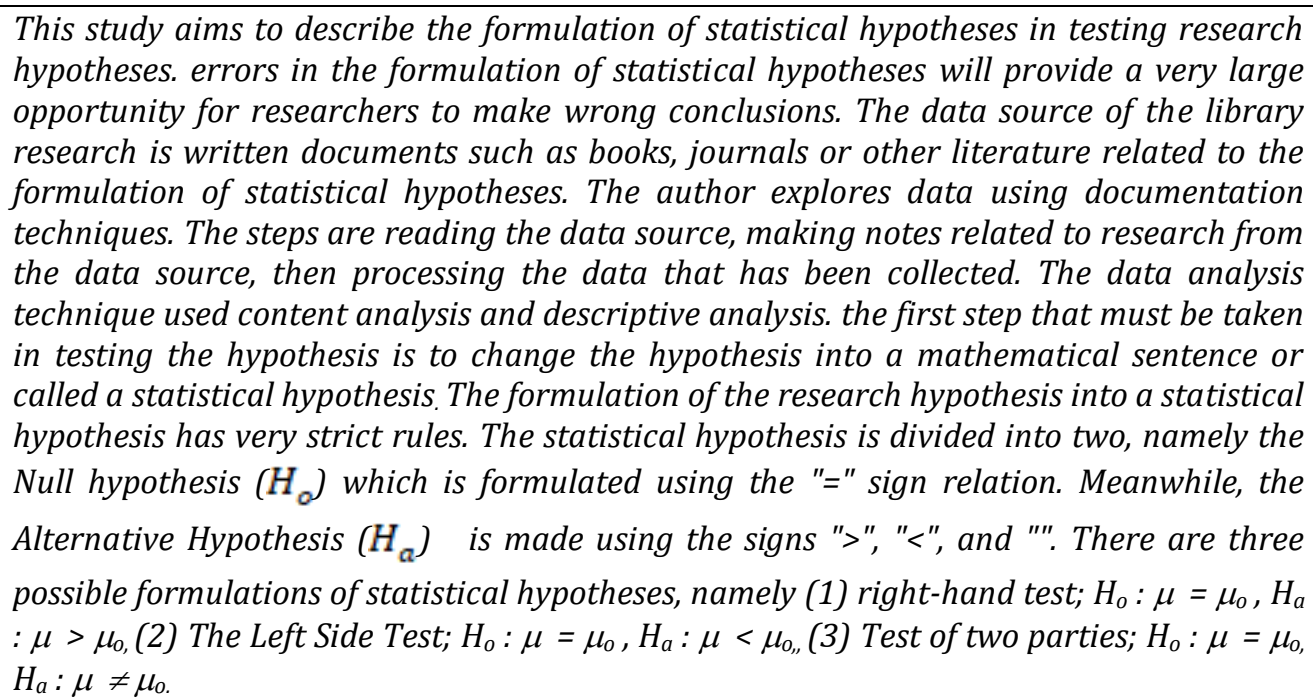 \\
\hline Artik & Abstrak \\
\hline $\begin{array}{l}\text { Sejarah Artikel } \\
\text { Diterima: 2021-01-12 } \\
\text { Direvisi: 2021-02-01 } \\
\text { Dipublikasi: 2021-03-16 }\end{array}$ & 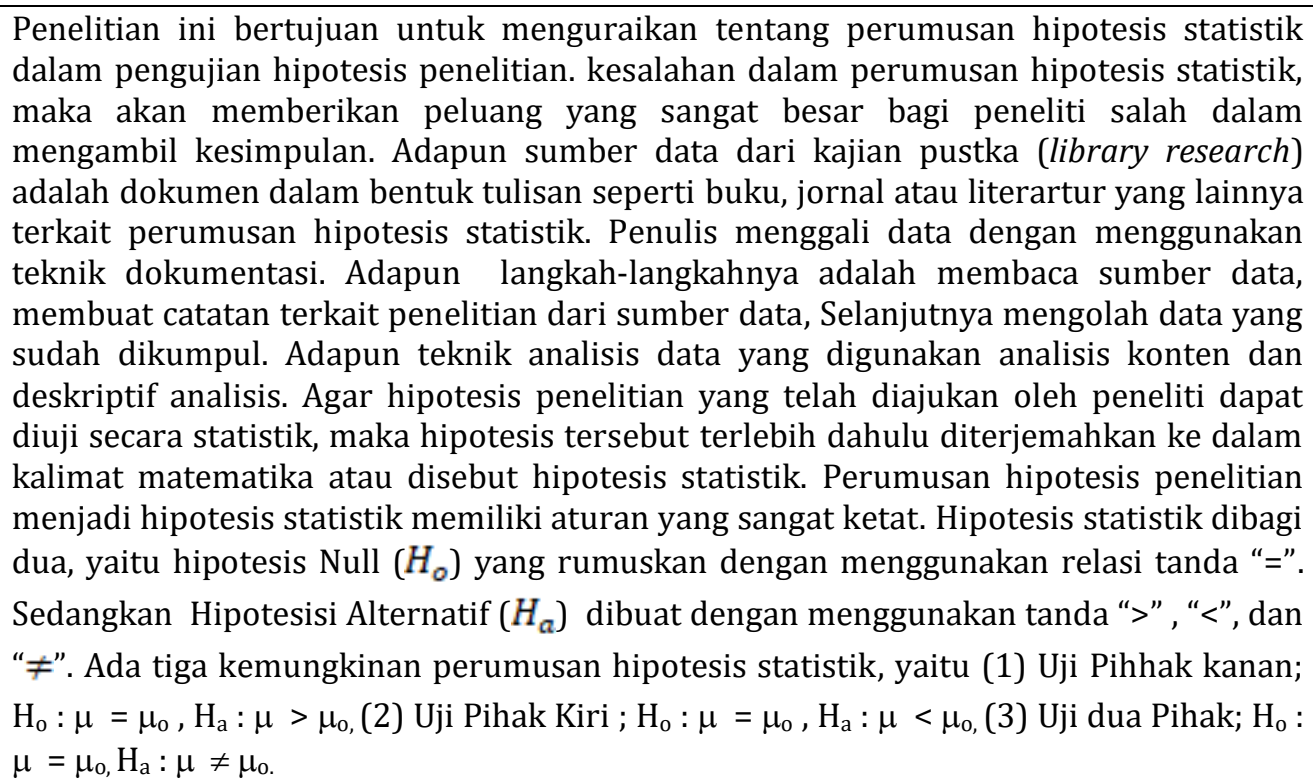 \\
\hline
\end{tabular}

\section{PENDAHULUAN}

Salah satu persyaratan menyelesaikan program sarjana strata satu (S1) bagi mahasiswa adalah penulisan skripsi, Penulisan skripsi sering disebut juga sebagai tugas akhir. Hal ini dikarenakan salah satu syarat utama seorang mahasiswa dapat mengikuti yudisium adalah telah memperta-hankan hasil tulisan (skripsi) di depan dewan penguji. Salah satu tujuan utama penulisan skripsi bagi mahasiswa adalah sebagai tempat mengaplikasikan ilmu yang telah dipelajari. Serta sebagai wahana melatih mahasiswa untuk melakukan penelitian. Melalui penelitian ini (skripsi) diharapkan mahasiswa dapat mengemba-ngkan pengetahuannya. Pelaksanaan penelitian tidak hanya menjadi tugas mahasiswa, para dosen pun juga dituntut untuk selalu melakukan penelitian, karena hanya dengan penelitian-penelitian tersebut dapat berkembangnya suatu ilmu. Bahkan 
tidak jarang teori-teori baru lahir karena adanya suatu penelitian.

Khusus bagi mahasiswa, sebelum melakukan penelitian dalam rangka menyelesaikan skripsi, mereka telah terlebih dahulu dibekali dengan berbagai mata kuliah yang menunjang pelaksanaan penelitian tersebut. pada Prodi Pendidikan Matematika, misalnya, diantara mata kuliah tersebut antara lain, metodologi penelitian, statistik, pengelohaan data dan ilmu-ilmu dasar lainnya yang sesuai dengan jurusan masing-masing. Melalui mata kuliah Metodologi Penelitian, mahasiswa telah dibekali dengan pengetahuan dasar tentang penelitian, seperti cara mendapatkan masalah, merumuskan masalah dan atau pertanyaan penelitian, merumuskan hipotesis, pengumpulan data, pengolahan, dan analisa data serta penarikan kesimpulan.

Kemampuan merumuskan hipotesis merupakan salah satu bagian yang sangat penting dalam penelitian, terutama untuk penelitian yang bersifat kuantitatif. Husaini (2011: 38), menyebutkan perumusan hipotesis berguna untuk: "(1) memfokuskan masalah, (2) mengidentifikasi data-data yang relevan untuk dikumpulkan, (3) menunjukkan bentuk desain penelitian, termasuk teknis analisis yang akan digunakan, (4) menjelaskan gejala sosial, (5) mendapatkan kerangka penyimpulan, dan (6) merangsang penelitian lebih lanjut". Selanjutnya untuk menentukan pengujian terhadap hipotesis yang telah dirumuskan, secara lebih mendalam dibahas dalam mata kuliah Statistik. Dalam mata kuliah Statistika, mahasiswa secara khusus dibekali dengan cara penentuan sampel dan pengolahan data, yang selanjutnya mengarah kepada pengujian hipotesis. Terutama data untuk penelitian yang bersifat kuantitatif.

Hipotesis yang diajukan oleh peneliti disebut dengan hipotesis penelitian. Agar hipotesis penelitian yang telah diajukan oleh peneliti dapat diuji secara statistik, maka hipotesis tersebut terlebih dahulu diterjemahkan ke dalam kalimat matematika. Hipotesis penelitian yang telah diubah dalam bentuk kalimat matematika disebut dengan hipotesis statistik. Hipotesis penelitian dapat ditulis ke dalam hipotesis statistik menjadi dua bagian, yang disebut dengan Hipotesis nihil $\left(\mathrm{H}_{0}\right)$ dan hipotesis alternatif $\left(\mathrm{H}_{\mathrm{a}}\right)$. Perumusan hipotesis penelitian menjadi hipotesis statistik memiliki aturan yang sangat ketat. Ini sesuai dengan karakteristik statistik sebagai cabang matematika yaitu konsisten dalam sistemnya. Selain itu, jika terjadi kesalahan dalam perumusan hipotesis statistik, maka akan memberikan peluang yang sangat besar bagi peneliti salah dalam mengambil kesimpulan.

Kajian ini beranjak dari kegelisahan penulis pada saat menilik ketidaksesuain fenomena empirik dan realita teoritis/ kondisi ideal yang diharapkan. Sejatinya, antara fenomena empirik dan realita teoritis harus sesuai. Berdasarkan pengalaman penulis sebagai pembimbing atau penguji seminar proposal skripsi dan sidang penguji seminar proposal skripsi, penulis menemukan kesalahan-kesalahan mendasar yang dilakukan mahasiswa dalam menerjemahkan hipotesis penelitian ke dalam bahasa matematika (hipotesis statistik). Kesalahan yang muncul sekilas terlihat merupakan kesalahan konsisten. Artinya kesalahan itu seperti mengacu kepada kesalahan yang sama dari setiap mahasiswa. Diantaranya kesalahan yang dilakukan adalah kesalahan pada saat merumuskan Hipotesis nihil $\left(\mathrm{H}_{\mathrm{o}}\right)$ dan hipotesis alternatif $\left(\mathrm{H}_{\mathrm{a}}\right)$, mahasiswa salah memilih tanda relasi pada pasangan hipotesis $H_{\circ}$ dan $H_{a}$. Berdasarkan pembahasan diatas, maka perlu dilakukan kajian teoritis yang lebih mendalam tentang perumusan hipotesis statistik atau terkait menerjemahkan hipotesis penelitian ke dalam bahasa matematika (hipotesis statistik). Adapun rumusan masalahnya adalah bagaimanakah perumusan hipotesis statistik pada pengujian hipotesis?

\section{METODE PENELITIAN}

Penulis mendapatkan sumber data dari perpustakaan atau dokumen dalam bentuk tulisan seperti jornal, referensi atau literartur yang lainnya. peneliti mencoba memecahkan satu gejala yang terjadi dengan menrumuskan konsep untuk menyelesaikan suatu permasalahan yang terjadi. peneliti mencoba menelaah tentang merumusan hipotesis statistik daru beberapa referensi-refrerensi. Oleh sebeb itu peneliti menggunakan jenis library research. Sumber data penelitian ini adalah buku statistik yang mengkaji tentang perumusan hipotesis. Peneliti menggali informasi atau data dari buku-buku statistik, jurnal atau literatur lainnya. Oleh sebab itu penelitian ini menggunakan teknik pengumpulan data dengan cara dokumentasi. Langkah-langkah pada teknik dokumentasi yang digunakan adalah pertama membaca sumber data, yaitu buku- buku atau referensi terkait perumusan hipotesis statistik. Kemudian peneliti membuat catatan terkait penelitian dari sumber data. Selanjutnya mengolah data yang sudah dikumpul. Adapun teknik analisis data yang digunakan analisis konten, peneliti menggunakan teknis analisis ini untuk memahami kontek buku terkait perumusan statistik. Kemudian penulis mencoba menguraikan tentang perumusan statistik dari buku atau referensi terkait, oleh sebab itu penulis juga menggunakan teknik deskriptif analisis.

\section{HASIL DAN PEMBAHASAN}

\section{A. Hipotesis Penelitian}

Hipotesis merupakan dugaan sementara atau jawaban sementara terhadap rumusan masalah atau pertanyaan penelitian yang masih harus diuji kebenarannya. Menurut weisstein dan eric $A$ hypothesis is a proposition that is consistent with known data, but has been neither verified nor shown to be false. Ketut (2007) mengemukakan bahwa hipotesis penelitian adalah pernyataan yang merupakan jawaban sementara terhadap rumusan 
masalah yang sifatnya menduga tetapi didasari oleh teori-teori atau temuan terdahulu. Dantes (2012) hipotesis adalah praduga yang harus diuji melalui data yang didapat dengan penelitian. Jadi karena hipotesis sifatnya masih menduga, maka hipotesis harus uji. Suharsimi (2010) juga mensinyalir, agar perhatian peneliti hanya terfokus pada informasi atau data yang diperlukan saja maka peneliti mencoba menyusun alternatif pemecahan untuk problema yang dimiliki, kemudian berusaha mencari informasi melalui penelitian untuk mencari bukti-bukti. Dalam hal ini peneliti diuji kemampuannya untuk "menebak secara ilmiah dan logis" tentang pemecahan problema yang dimiliki. Tebakan pemecahan yang diusulkan inilah yang biasanya diistilahkan dengan hipotesis.

Secara bahasa hipotesis berasal dari kata hipo berarti kurang atau lemah dan tesis atau thesis yang berarti teori yang disajikan sebagai bukti Dantes (2012). Dalam pembicaraan ini hipo diartikan lemah dan tesis diartikan teori. Jadi hipotesis adalah pernyataan yang masih lemah kebenarannya dan masih perlu dibuktikan kenyataannya. Hipotesis merupakan alternatif dugaan jawaban yang dibuat oleh peneliti bagi problematika yang diajukan dalam penelitiannya.

Menurut Narbuko (2013), hipotesis dapat bersumber dari pengalaman-pengalaman praktek, teori-teori, kesan-kesan hasil diskusi, pembahasan-pembahasan dalam perpustakaan, dan sebagainya. Merumuskan hipotesis sebenarnya tidak ada aturan umum, namun hipotesis dapat dikatakan baik apabila memenuhi empat buah kriteria, Suharsimi (2010) mengemukakan sebagai berikut,

1. Hipotesis hendaknya menyatakan rumusan tentang hubungan antara dua variabel atau lebih.

2. Hipotesis hendaknya dirumuskan sacara jelas, singkat, dan padat

3. Hipotesis mungkin untuk diuji.

Hipotesis dirumuskan hendaknya disertai dengan alasan atau dasar-dasar teoritik, dan dinyatakan dalam kalimat pernyataan.

\section{B. Perumusan Hipotesis Statistik}

Hipotesis penelitian sebelum diuji secara statistik, harus terlebih dahulu ditulis dalam bahasa matematika yang disebut dengan hipotesis statistik. Ketut (2002) menyebutkan "Hipotesis statistik adalah dugaan tentang parameter suatu populasi". hipotesis statistik terbagi kedalam dua bagian yaitu hipotesis nihil/null dan hipotesis alternatif

1. Hipotesis Null atau Hipotesis Nihil $\left(\mathrm{H}_{\mathrm{o}}\right)$

Hipotesis null adalah hipotesis yang menyatakan ketidakadanya hubungan antara variabel, contohnya. Tidak ada hubungan antara nilai Matematika dengan nilai IPA. Suharsimi (2009).
Hipotesis Null adalah hipotesis yang tidak ada perbedaan, tidak berefek, tidak ada pengaruh, makanya hipotesis null juga disebut Hipotesis Nihil, hipotesis yang tidak ada apaapanya (nihil). Menurut Ketut (2002), $\mathrm{H}_{\mathrm{o}}$ selalu dirumuskan dengan dengan tanda sama dengan $(=)$, sehingga menspesifikasi suatu nilai tunggal artinya tanda "=" akan memberikan satu nilai. Dengan cara ini peluang melakukan galat jenis I(kesalahan jenis I) dapat dikendalikan atau memudahkan peneliti untuk mengontrolnya. weisstein dan eric mengkonfirmasi bahwa "identify a test statistic that can be used to assess the truth of the null hypothesis", artinya Hipotesis Null adalah yang diuji.

\section{Hipotesis Alternatif $\left(\mathrm{H}_{\mathrm{a}}\right)$}

Hipotesis alternatif atau hipotesis kerja adalah hipotesis yang menyatakan hubungan antara variabel. Suharsimi (2010). Menurut weisstein dan eric "The alternative Hypothesis $\left(H_{a}\right)$, commonly, that the observations show a real effect combined with a component of chance variation". Hipotesis Alternatif $\left(\mathrm{H}_{\mathrm{a}}\right)$ adalah lawan dari Hipotesis Null, yaitu hipotesis yang menyatakan ada perbedaan, ada efeknya, ada pengaruh atau ada hubungan, ada apa-apanya dengan berbagai alternatif. Hipotesis Alternatif $\left(\mathrm{H}_{\mathrm{a}}\right)$ dirumuskan dengan relasi ">”, "<", dan “ $\neq$ ". Weisstein mengkonfirmasi bahwa The alternative hypothesis is usually taken to be that the observations are the result of a real effect.

Berdasarkan perumusan hipotesis null $\left(\mathrm{H}_{\mathrm{o}}\right)$ dan hipotesis alternatif $\left(\mathrm{H}_{\mathrm{a}}\right)$ di atas, ada tiga Kemungkin pasangan hipotesis statistik, yaitu:

1. Uji Pihhak kanan

$\mathrm{H}_{\mathrm{o}}: \mu=\mu_{\mathrm{o}}$

$\mathrm{H}_{\mathrm{a}}: \mu>\mu_{\mathrm{o}}$

2. Uji Pihak Kiri

$\mathrm{H}_{\mathrm{o}}: \mu=\mu_{\mathrm{o}}$

$\mathrm{H}_{\mathrm{a}}: \mu<\mu_{\mathrm{o}}$

3. Uji 2 Pihak

$\mathrm{H}_{\mathrm{o}}: \mu=\mu_{\mathrm{o}}$

$\mathrm{H}_{\mathrm{a}}: \mu \neq \mu_{\mathrm{o}}$

Memilih salah satu diantara tiga kemungkin pasangan hipotesis statistik sangat tergantung klaim/dugaan/hipotesis penelitian sedemikian hingga hipotesis penelitian hanya terletak disalah satunya $\mathrm{H}_{\mathrm{o}}$ saja atau $\mathrm{H}_{\mathrm{a}}$ saja.

Contoh:

1. Seorang peneliti mengklaim bahwa rata-rata kandungan nikotin dalam sebatang merek $\mathrm{x}$ melebihi $1 \mathrm{mg}$. Rumuskan hipotesis statistik untuk menguji klaim!

Hipotesis Statistik: 
$\mathrm{H}_{\mathrm{o}}: \mu=1$

$\mathrm{H}_{\mathrm{a}}: \mu>1$

Hipotesis peneliti terletak di $\mathrm{H}_{1}$

2. Seorang peneliti mengklaim bahwa dengan model Cooperatif tipe Numered Head Together hasil belajar siswa mencapai minimal 80 point. Rumuskan hipotesis statistik untuk menguji klaim peneliti.

Hipotesis Statistik:

$$
\begin{aligned}
& \mathrm{H}_{\mathrm{o}}: \mu=80 \\
& \mathrm{H}_{\mathrm{a}}: \mu<80 \text { hipotesis peneliti }
\end{aligned}
$$

3. Seorang peneliti mengklaim bahwa rata-rata kandungan nikotin dalam sebatang merek $\mathrm{x}$ tidak melebihi $1 \mathrm{mg}$. tentukan rumusan $\mathrm{H}_{\mathrm{o}}$ dan $\mathrm{H}_{\mathrm{a}}$ untuk menguji klaim sang penguji 1 .

Hipotesis yang salah :

$$
\begin{array}{ll}
\mathrm{H}_{\mathrm{o}} & : \quad \mu=1 \\
\mathrm{H}_{\mathrm{a}} & : \quad \mu \leq 1
\end{array}
$$

Sebab dalam hal ini hipotesis terletak di $\mathrm{H}_{\mathrm{o}}$ dan $\mathrm{H}_{\mathrm{a}}$

Hipotesis statistik :

$$
\begin{array}{ll}
\mathrm{H}_{\mathrm{o}} & : \quad \mu=1 \\
\mathrm{H}_{\mathrm{a}} & : \quad \mu>1
\end{array}
$$

Dalam hal ini hipotesis terletak di $\mathrm{H}_{\mathrm{o}}$

4. Seorang peneliti mengklaim bahwa rata-rata kandungan nikotin dalam sebatang merek $\mathrm{x}$ kurang $1 \mathrm{mg}$. tentukan rumusan $\mathrm{Ho}$ dan $\mathrm{H}_{\mathrm{a}}$ untuk menguji klaim sang penguji 1.

Hipotesis :

$$
\begin{array}{ll}
\text { Ho } & : \quad \mu=1 \\
\mathrm{H}_{\mathrm{a}} & : \quad \mu<1
\end{array}
$$

Dalam hal ini hipotesis terletak di $\mathrm{H}_{\mathrm{a}}$

\section{SIMPULAN DAN SARAN}

\section{A. Simpulan}

Hipotesis Penelitian adalah jawaban sementara terhadap rumusan masalah/pertanyaan penelitian yang sifatnya menduga tetapi juga dilandasi oleh teori-teori atau temaun terdahulu. Karena sifatnya masih menduga oleh sebab itu hipotesisi penelitian harus diuji secara empirik atau diistilahkan dengan pengujian hipotesis. Dalam pengujian hipotesis, terlebih dahulu hipotesisi penelitian harus diubah dalam kalimat matematika atau disebut dengan hipotesis statistik. Hipotesis statistik dibagi dua, yaitu hipotesis Null $\left(H_{\circ}\right)$ yang rumuskan dengan menggunakan relasi tanda "=" . Sedangkan Hipotesisi Alternatif $\left(H_{a}\right)$ dibuat dengan menggunakan tanda ">” , “<”, dan “ $\neq$ ". Ada tiga kemungkinan perumusan hipotesis statistik, yaitu (1) Uji Pihhak kanan; $\mathrm{H}_{\mathrm{o}}: \mu=\mu_{\mathrm{o}}, \mathrm{H}_{\mathrm{a}}: \mu>\mu_{\mathrm{o}}$, (2) Uji Pihak Kiri ; $\mathrm{H}_{\mathrm{o}}: \mu=\mu_{\mathrm{o}}, \mathrm{H}_{\mathrm{a}}: \mu<\mu_{\mathrm{o}}$, (3) Uji dua Pihak; $H_{o}: \mu=\mu_{o}, H_{a}: \mu \neq \mu_{o}$.

\section{B. Saran}

Adapun saran yang dapat disampaikan berdasarkan hasil library research ini, yaitu: (1) peneliti dalam merumuskan hipotesis statistik harus benar-benar memperhatikan aturan-aturan perumusannya. (2) kajian ini merekomendasi kepada khalayak peneliti dalam perumusan hipotesis statistik sehingga tidak salah dalam mengambil keputusan..

\section{DAFTAR RUJUKAN}

Arikunto, Suharsimi. 2010. Manajemen Penelitian. Jakarta : PT RINEKA CIPTA.

Asmedy. (2021). Perbedaan Hasil Belajar Siswa yang Diajar Menggunakan Model Pembelajaran Soal Terbuka dengan Model Pembelajaran Konvensional. Ainara Journal (Jurnal Penelitian Dan PKM Bidang Ilmu Pendidikan), 2(2), 79-88. Retrieved from http://journal.ainarapress.org/index.php/ainj/a rticle/view/36

Budayasa, Ketut. 2007. Catatan Statistik: Pendidikan Matematika Program Pasca Sarjana Universitas Negeri Surabaya.

Dantes, Nyoman. 2012.Metode penelitian. Yogyakarta: Andi

Department of Statistics. Staststics Online : hypothesis testing : PennState (online) (https://online.stat.psu.edu/statprogram/reviews /statistical-concepts/hypothesis-testing .Diakses tanggal 1 Maret 2021)

Eka Yulianti, \& Taufik. (2020). Studi Perbandingan Eksistensi Alam Pada Novel Tanah Baru Tanah Air Kedua Karya Nh. Dini Dan Sri Rinjani Karya Eva Nourma (Tinjauan Ekologi Sastra). Ainara Journal (Jurnal Penelitian Dan PKM Bidang Ilmu Pendidikan), 1(2), 44-55. https://doi.org/10.1234567/ainarajournal.v1i2. $\underline{13}$

Husaini Usman dkk. 2011. Metodologi Penelitian Sosial (Edisi II). Jakarta: Bumi Aksara.

Narbuko, Cholid\& Ahmadi, Abu. 2013. Metodologi Penelitian. Jakarta: Bumi Aksara

Taufik, Erwin, \& Husnul Khatimah. (2020). Model Pembelajaran CIRC pada Mata Kuliah Apresiasi Sastra "Mantra Mbojo" untuk Meningkatkan Kreativitas Mahasiswa. Ainara Journal (Jurnal Penelitian Dan PKM Bidang Ilmu Pendidikan), 1(2), 62-70. https://doi.org/10.1234567/ainarajournal.v1i2. $\underline{15}$

Weisstein, Eric W. "Hypothesis Testing." From MathWorld--A Wolfram, (online), (https://mathworld.wolfram.com/HypothesisTesti ng.html. Diakses tanggal 2 Maret 2021.) 